\title{
Journal citation measures: a concise review ${ }^{*}$
}

\author{
R. Todorov \\ Centre for Scientific Information. Bulgarian Academy of Scien- \\ ces, 7 Noemeri Street. BG-1040. Sofia. Bulgaria
}

\section{W. Glänzel}

Libran of the Hungarian Academy of Sciences, Department for Scientometrics, P.O. Box $7 \mathrm{H}-1361$, Budapest 1 , Hungan

Received 19 May 1987

A cross-citation matrix with journal titles in the rows and the columns is examined. Journal citation measures are reviewed within the matrix framework. Some limitations of traditional indicators such as immediacy index and impact factor are discussed. Time-related and other journal citation measures are also presented. Relations between joumal citation measures, and objective and subjective ratings of scientific journals are briefly described and commented upon.

\section{Introduction}

Scientific journals are the most important sources of refereed articles. There is a vast literature on their functions and characteristics [8.41.56]. The term 'scientific' refers more to the subject matter and covers 'traditional' sciences. Nowadays it is used also for applied. social. and behavioural sciences adopting more and more "the canons of inquiry that dominate the natural sciences" [35]. All these sciences are characterized by "a kind of pattern of rather tight-knit cumulative structure, in which contributions are made in a positive, definite, and finished form (at least, temporarily!), and each advance is made on the basis of immediately prior contributions" [14, p.82]. In this sense it is natural that reference practices have been adopted and matured in journal articles in such disciplines "striving for, and insisting on, a

\footnotetext{
* A new version of a paper presented by the first author at the International Seminar on Information Research. Dubrovnik (Yugoslavia), May 19-24, 1986. The full proceedings are published as: N. Tudor-Silovic. Ed.. Information Research. Research Methods in Libran' and Information Science (Taylor Graham, London, 1987).
}

\section{North-Holland}

Journal of Information Science 14 (1988) 47-56 consensus" [39, p.13]. The tradition of giving references to previous publications (especially in journals) and to take into consideration the citations received from newly appeared scientific papers took new dimensions with the emergence, adoption, and wide use of Science Citation Index (SCI). Conceived as an indexing and retrieval tool [20] it is used also in science studies: mapping the structure of science [34]. validation of individual or group performance [23]. etc. The introduction of Journal Citation Reports (JCR) as a companion volume to SCI has extended the use of citation analysis to examine relationships among journals whose purpose is "the communication of original research findings and the indispensable summary of research findings provided by reviews" [22]. The journal citation data in JCR are compiled by counting the different article-to-article links. As a result the references from. and citations to. a journal are given as well as their distribution over time. These and other data are further used for constructing journal measures (or indicators [ 30. p.53]) such as impact factor (IF), immediacy index (II), references per paper $(\mathrm{R} / \mathrm{P})$, half-life $(\mathrm{HL})$. etc., assuming implicitly that aggregating the article-to-article citations (without making explicit the nature of these links) one can represent journals' relatedness and arrive at a certain measure (in most cases an average) of journal influence.

Journal citation indicators are commonly used as general measures for various journal characteristics and research impact by different participants in the publication. dissemination, and evaluation process of scientific knowledge. They are more or less concerned with journal selection and ranking as journals are "numerous, unwieldly diversified in subject matter, and highly stratified in both function and prestige" [50]. Many librarians, information scientists and sociologists of science already consider journal citation analysis as a practical alternative to subjective judgement. Authors may take citation measures from JCR and use them as possible indicators of journal characteristics. Lists of ranked SCI journals may help potential and real users to identify sources with significant contributions. Editors and publishers may relate high citation impact to a suc- 
cessful editorial practice and policy. That is why we are trying in this paper to review and comment on some citation-based measures for scientific journals which are available and applied as evaluative indicators.

\section{Measures based on journal citation links}

The tabulation of journal references to other journal titles (or the recording of the article-toarticle links) in a cross-citing matrix is used (implicitly and explicitly) for deriving appropriate measures for journal interactivity and impact within an area of science and for specified periods of time. The traditional citation matrix consists of journal titles in the rows (citing sources) and the columns (cited journals), and is formed by 'cells' $C_{1}$ (see Table 1). A matrix cell records the number of references $C_{11}$ that the source journal $J_{4}$ gives (out) to destination (column) journal $J_{\mathrm{d},}$. The row sum $R_{1}=C_{11}+\cdots+C_{1 m}$ represents the total number of references given from $J_{s}$ to other tabulated journals. The element $C_{1}$, indicates also the number of citations received by $J_{\mathrm{d}}$, from $J_{s}$. The column sum $C_{1}=C_{1},+\cdots-C_{n}$, is the total number of citations received by $J_{\mathrm{d}}$, from the matrix source journals. This important type of matrix may be thought of as representing the process of transaction of references (or citations) [16, p.55] among journals. This matrix is asymmetric with relatively high values in the diagonal where self-citations are registered.

References are extracted from (substantive) papers $P_{\mathrm{s}}$ (full length articles, letters, notes, reviews) of standard journals $J_{\mathrm{s},}$ published in a period $t_{r}$ (usually $t_{r}=1$ year). The set of source or citing journals is selected using different criteria, techniques and indicators. The existence of JCR makes it possible to extend the number of citing $(n)$ and cited $(m)$ journals to hundreds of SCI journals and in the same time to differentiate between types of papers and journals.

A simple (row) ranking of journals could be established directly according to the number of citations received in a specified set of journals. In order to increase reliability and reduce undue influence of idiosyncratic issues of some journals $J_{\triangleleft}, t_{r}$ could be extended [38].

The time frame $t$, of the matrix or the period of time in which the cited papers $P_{\mathrm{s}}$, are published [29], is important for constructing appropriate measures and their interpretation. The references given may be to papers published in any year up through the year $t_{r}$. Often it is assumed that the journals from a matrix to be analysed do not change considerably between the time period $t$. and $t_{r}$. and represent a 'constant' subject area [31].

Journal citation measures are obtained either by including or excluding the number of published papers (journal size), and by varying $n$ (source journals). $m$ (cited journals), and the time frame of the matrix. Several measures such as citation rate ( $C$ ). IF, II. $\mathrm{R} / \mathrm{P}$ are quite popular because of their early introduction, relatively simple definition and interpretation, and availability in the JCR. However, some limitations arise in their application. The total number of citations received by a journal in a given year $\left(C_{1}\right)$ obviously depends on the size (or productivity) of the journal, i.e. the number of citable items, the subject area,

Table 1

Cross-citation matrix with elements $C_{1,}$ or distribution of references over journals cited

\begin{tabular}{|c|c|c|c|c|c|c|c|c|c|c|c|c|}
\hline \multicolumn{5}{|c|}{ Time period $t_{r}$} & & \multicolumn{5}{|c|}{ Time period $t_{\mathrm{c}}$} & \multirow[b]{2}{*}{$\leftarrow$} & \multirow[b]{2}{*}{$\begin{array}{l}\text { Destination or cited journals } \\
\text { Citable items }\end{array}$} \\
\hline $\begin{array}{l}\text { Source } \\
\text { journals }\end{array}$ & & Papers & & $\begin{array}{l}\text { References } \\
\text { (row sums) }\end{array}$ & & $\begin{array}{c}J_{\mathrm{dl}} \\
P_{\mathrm{dl}} \\
\downarrow\end{array}$ & $\begin{array}{l}\cdots \\
\cdots\end{array}$ & $\begin{array}{l}J_{\mathrm{d},} \\
P_{\mathrm{d}} \\
\downarrow\end{array}$ & $\cdots$ & $\begin{array}{l}J_{\mathrm{J} m} \\
P_{\mathrm{d} m} \\
\downarrow\end{array}$ & & \\
\hline$J_{s 1}$ & $\rightarrow$ & $P_{\text {sl }}$ & $\rightarrow$ & $\begin{array}{l}R_{1} \\
\vdots\end{array}$ & $\rightarrow$ & $C_{11}$ & $\ldots$ & $C_{1,}$ & $\cdots$ & $C_{1 m}$ & & \\
\hline$J_{s t}$ & $\rightarrow$ & $P_{\mathrm{st}}$ & $\rightarrow$ & $R$ & $\rightarrow$ & $C_{11}$ & $\ldots$ & $C_{1 j}$ & $\ldots$ & $C_{I m}$ & & . \\
\hline$J_{s n}$ & $\rightarrow$ & $P_{\mathrm{s} n}$ & $\rightarrow$ & $R_{n}$ & $\rightarrow$ & $\begin{array}{c}\mid C_{n 1} \\
\downarrow \\
C_{1}\end{array}$ & $\cdots$ & $\begin{array}{l}C_{n j} \\
\downarrow \\
C_{j}\end{array}$ & $\cdots$ & $\begin{array}{l}C_{n m} \\
\downarrow \\
C_{m}\end{array}$ & $\leftarrow$ & Column sums or citations \\
\hline
\end{tabular}

Journals $J_{s,}$ and $J_{d}$ are the same titles taken usually in different time periods. Full coincidence is realised only by $t_{r}=t_{c}$. 
and other factors. Accordingly, this measure has no meaning on an absolute scale. It has been used for selection of relevant journals in the field of acoustics [1] and it has become evident that multidisciplinary journals (which publish a considerable number of papers) could not be isolated. Pinski and Narin [31] have proposed to normalize $C$, by the number of references given. The ratio $C_{1} / R_{\text {, }}$ thus obtained could be further used for constructing more 'subtle' measures. The same ratio is mentioned by Price [16.p. 59] as a quality index of scientific journals. It is also introduced as a component of a 'synthetic' citation measure called the consumption factor [58] and defined as

\section{Consumption factor}

$$
\begin{aligned}
& =\text { citation factor } \times \text { popularity factor } \\
& =\frac{\text { citations }}{\text { references }} \times \frac{\text { citing journals }}{\text { cited journals }} \\
& =C_{1} / R, \times J_{\mathrm{s}} / J_{\mathrm{d}} .
\end{aligned}
$$

Some limitations of the citation factor (such as high values for applied and technical journals) and the popularity factor are described [53]. It is shown that the consumption and the impact factor are statistically independent which suggests that these two measures represent distinct journal attributes [37].

Reduction of size is possible (e.g. taking $C_{1,} / R$, or $C_{1}, C_{1}$ ) and appropriate when each journal is treated on an equal basis. Pinski [32] has proposed another size-independent measure by dividing the matrix elements $C_{1}$, by the geometric mean of the corresponding diagonal elements $C_{11}$ and $C_{1 \prime}$. So instead of citation rate a measure of cited interactivity is constructed and at the same time the influence of self-citation is reduced.

The quantitative excess of self-citations as compared to the off-diagonal elements is analysed by Price [16] and Noma [27]. Different techniques are proposed to deal with the (large) diagonal elements for further analysing cross-citation or more generally transaction matrices. One can ignore the self-citations in the matrix [48] or replace them by other values [54]. Price's procedure consists of replacing "the diagonal terms $C_{1}$ by those that could be there if each member journal treated itself in just the same way as it treats others" [16]. The new diagonal elements $E_{t}$ are calculated on the basis only of the off-diagonal elements. In the case of a square matrix $(n \times n)$ the $E_{a}$ are ex- pressed mathematically as follows:

$$
E_{14}=\frac{\left(\prod_{1} C_{1,} \prod C_{1,}\right)^{1 / n-2}}{\prod_{1}\left(\prod_{j} C_{1 j}\right)^{1 / n-1}} .
$$

Refining Price's procedure Noma [27] has proposed an iterative calculation of expected diagonal elements $e_{\|}$using a loglinear model:

$$
\begin{aligned}
e_{11}= & \frac{\left(R_{1}-C_{11}\right)\left(C_{1}-C_{11}\right)}{\left(R_{1}-C_{11}\right)} \\
& -\left(R_{1}-C_{11}\right)-\left(C_{1}-C_{11}\right) .
\end{aligned}
$$

with $R$, and $C_{1}$ denoting correspondingly the $i$ th row and column sums.

Self-cited $\left(C_{1} / C_{1}\right)$ and self-citing $\left(C_{11} / R_{1}\right)$ rates are measures which relate the number of self-citations to the number of citations received and correspondingly to the number of references given to other journals. Self-cited rate appears to be relatively low for known and 'leading' journals in a given field and high for peripheral journals [ 20 . p.150]. These two measures depend heavily on the 'closeness' of the subject field and the availability of more than one leading journal in the considered speciality. In principle, review journals have negligible self-citation rates.

Instead of self-citing rate a measure of -domesticity' $D$ has been used [10] with $D=\left(C_{11}-E_{u}\right) / R$, where the $E_{11}$ are the expected values already introduced [16]. This measure could be applied to discriminate between journals with different orientation and origin [53].

The number of references per paper $(R / P)$ is the simplest measure in which the total number of references is normalized for the size of the source (citing) journal. The number of items used is not always confined to traditional articles, letters, notes, and reviews [57]. The $R / P$ is a mean value and traditionally is given without description of its deviations. It depends on the citation practices existing in a field but does not necessarily correlate with the field population [20, p.248]. The number of references per paper is rather low in mathematics and relatively high in biomedicine [21]. Values for $R / P$ are available in the JCR and are used for discrimination between original research articles and review papers.

The immediacy index (II) indicates "how 
rapidly a journal's material is picked up and used" [20. p. 150]. It represents the average number of citations received by a journal in a specific year $t_{r}$ to articles published in the same year $\left(t_{c}=t_{r}\right)$. As this measure superimposes citation rate and citation speed [3] it depends on such factors as periodicity, publication delay, circulation size. language. etc.

The journal impact factor (IF) is an average number of citations received by a journal in a given year $\left(t_{r}\right)$ to articles published during the previous two years, i.e.

$t_{\mathrm{c}}=\left(t_{r}-1\right)+\left(t_{r}-2\right)$.

As IF is normalized for the number of papers published in the time period $t_{c}$ it discards existing differences in journal size. publishing frequency, and age [49]. Some limitations are discussed of this largely used indicator:

- there is no normalization for reference practices and traditions in the different fields and disciplines [31]:

- citations received are unweighted or "there is no distinction in regard to the nature and merits of the citing journals" [12];

- it is biased towards journals with larger papers. e.g. review journals tend to have higher impact factors [31]:

- citation frequency obtained is inaccurate because of age bias, i.e.. row frequency of journal citations is confined to a period of one year [36]:

- there is no indication of the deviations of this statistic (of a skewed distribution);

- the average span for a journal article to peak in citations is not always two years, or as Garfield puts it "if we change the two-year based period used to calculate impact, some type of journals are found to have higher impacts" [26].

To correct some of these limitations 'more appropriate' measures are proposed. The Disciplinary Impact Factor (DIF) is introduced as the average number of times a journal is cited in a given subfield alone rather than across the set of SCI index [29]. The source journals are determined by an iteration procedure and the introduction of more or less subjective cut-off criteria seems indispensible. One can use an impact factor with $t_{r}=t_{r-4}$ and instead of $t_{r}$ the sum $t_{r}+t_{r-1}$ $+\ldots+t_{r-4}=5$ years. This new 'dyachronic' IF is the average number of citations received by articles from a given year during this year and the next four years. Values of such IF for six Japanese journals in pharmacology and pharmacy are given in Table 2.

According to Asai [36] the period count based on a month produces more accurate statistics than that based on a year. This author develops a method for adjusting the row frequency $C$, using the probability theory. This Adjusted Impact Factor (AIF) includes, instead of $C_{r r}$ (citations in the year $t_{r}$ ). a sum of citations from the year $t_{r-3}$ up through the year $t_{r}$ :

$\mathrm{AIF}_{1}=\frac{1}{P_{\mathrm{d} t}}\left(\frac{1}{4} C_{1 r}+\frac{7}{4} C_{1 r-1}+\frac{7}{8} C_{1 r-2}+\frac{7}{8} C_{1 r-3}\right)$.

Citations are (as by traditional IF) to papers $P_{\mathrm{d}}$ published in the period $t_{\mathrm{i}}=t_{r-1}+t_{r-2}$.

Influence measures have been developed which allow the counting of references from leading (more cited) journals more heavily [31]. Such a measure $(w)$ is weighted by the influence of the source journal and normalized by the size of the cited journal as follows:

$n_{1}=\sum_{k} n_{h} C_{h_{1}} / R_{1}$

This influence weight $w$, represents the expected number of citations which the journal $J_{d}$, will receive per reference. The cross-citation matrix in

Table 2

Publication and citation data for six Japanese journals in pharmacology and pharmacy

\begin{tabular}{|c|c|c|c|c|}
\hline Title & A & B & C & $\mathrm{D}$ \\
\hline $\begin{array}{l}\text { Chemical and Pharma- } \\
\text { ceutical Bulletin }\end{array}$ & 529 & 13 & 3.78 & 0.18 \\
\hline Folia Pharmacologica & & & & \\
\hline Japonica & 72 & 56 & 1.31 & 0.30 \\
\hline Journal of Antibiotics & 228 & 7 & 8.02 & 0.69 \\
\hline Journal of Pharmacobio- & & & & \\
\hline Dynamics & 57 & 14 & 3.23 & 0.44 \\
\hline $\begin{array}{l}\text { Japanese Journal of } \\
\text { Pharmacology }\end{array}$ & 126 & 25 & 3.48 & 0.43 \\
\hline $\begin{array}{l}\text { Yakugaku Zasshi-Journal } \\
\text { of the Pharmaceutical } \\
\text { Society of Japan }\end{array}$ & 207 & 49 & 1.14 & 0.12 \\
\hline
\end{tabular}

A: Number of 1979 publications.

B: Percentage of uncited articles in the period from 1979 to 1983

C: Impact Factor

D: Standard deviation of Impact Factor (for the calculation see $[57])$ 
this case contains the same number of source and destination journals. Two other influence measures are also defined: influence per publication $\left(w, R, / P_{\mathrm{d}}\right)$ and total influence of a journal $(u, R$,$) .$ Geller [46] suggests a "corrected" influence weight $w^{*}$ which in the citation context could be interpreted as the probability that the journal $J_{d}$, will be cited. i.e. receive proportions of references $C_{k_{l}} / R_{k}$ from the other journals $J_{s h}$ in the matrix. This measure corresponds to the total influence of Pinski and Narin [31], and is given by

$w_{1}^{*}=\sum_{h} w_{k}^{*} C_{h i} / R_{k}$.

This procedure is refined by introducing proportions of all references instead of those confined to the matrix under consideration [54]. The achieved 'accuracy' is, however, at the expense of simple interpretation.

\section{Pure time related measures based on journal cita- tions}

Journal citation measures (derived from the cross-citation matrix) depend on the particular year(s) of observation $\left(t_{r}\right)$ and the publication period $\left(t_{\mathrm{c}}\right)$ of the articles cited. i.e. they are timerelated measures. Journal citation analysis deals also with distribution of references and citations explicitly by time periods (years). Formulated in another way, the temporal behaviour of journal references (or citations) is described: in synchronous analyses, the percentage of references given (or citations received) is plotted against the publication years of the cited items. Such chronological distributions of references (or citations) are traditionally characterized by their citing (and correspondingly cited) half-life (HL). These measures are defined in the JCR as the number of journal publication years from the current year $\left(t_{r}\right)$ back whose articles account for $50 \%$ of the total references given (or citations received) in that year. In other words. HL represents the median age of the literature which is cited by other articles in a given year. Truncated chronological distributions and HL values are given in JCR, without indication of HL deviations. For that reason chronological distributions of journal references or citations could by compared by introducing additionally the value. for instance of "quarter-life": the number of jour- nal publication years from the current year back whose articles account for $25 \%$ of the total references (or citations) in that year.

The relation between $\mathrm{HL}$ and indicators of literature obsolescence is largely discussed by librarians [17.33]. Obsolescence (defined as "decline over time in validity or utility of information" [43]) is traditionally measured by the decrease in use of literature. Measures are based on circulation or reshelving statistics. taking into account (or not) such factors as literature size. growth, etc. Applying citation measures instead is rejected [33] as the relationship between a decline of citations and a decrease in utility of items is uncertain. So the optimization of retention schedules in libraries should not rely on citation-based measures only.

Citing HL is used as an indicator of journal quality and citing practices of specific groups of authors [47].

Price [13] has introduced a (size independent) citation measure to describe the 'hardness' or the "softness" of a scientific discipline. This time-related measure represents simply the fraction of references (in a set of articles) given to items published in the recent five years. As mentioned earlier such proportion of recent references is a general indicator of age and does not take into account growth rate and differences in sources cited. It has been used as an indicator of journal characteristics [37].

Recently a new time-related indicator of journal citation speed has been introduced [3]. The time-lag between the publication year of an article and the date (year) of its first citation is defined as its response time. The Mean Response Time (MRT) of a journal (the new measure) is the

Table 3

Mean Response Tıme for some physies journals (ın years) ${ }^{a}$

\begin{tabular}{ll}
\hline Title & \\
\hline Annals of Physics & 0.9 \\
Applied Physics & 0.9 \\
Applied Physics Letters & 0.7 \\
Hyperfine Interactions & 0.6 \\
Journal of Physics B & 0.7 \\
Journal of Physics C & 0.8 \\
Physics Letters B & 0.6 \\
Physical Review Letters & 0.4 \\
Physica B and C & 1.1 \\
\hline
\end{tabular}

For the calculation see [3]. 
exponential average over five years. In Table 3 are given MRT values for some physics joumals.

\section{Other citation-based measures}

The percentage of uncited journal articles over a given time period (from all articles with some publication date) could be used as a measure of citation response. Garfield [23] has studied how often 1978 papers are cited in the next five years (1978-1982) and has revealed that even high prestige journals publish articles that never get cited. The ratio of items cited to items published for Nature and Science is correspondingly $96.2^{\circ} \mathrm{C}$ and $94.9 \%$, i.e. $3.8 \%$ and $5.1 \%$ of the published articles are not cited after a period of five years.

The fraction of uncited articles is not available in the JCR. It depends largely on the the referencing practices in the given field and the choice of citation years (as peak citation years for journals differ).

The number of highly cited papers in a journal (most of which appear as core documents of established research fronts) could be used as a measure for identification of reputable journals. For instance, highly cited physics papers (in the two years following publication) are concentrated only in six journals: Physical Review Letters, Physics Letters B, Nuclear Physics B, Science, Physical Review D, and Physical Review B [24.25].

The average number of references to research fronts (established by co-citation analysis) could be used as a measure for review articles and journals [55].

The Popularity Factor (ratio of citing to cited journals) should also be mentioned in this section. This measure appears to characterize better other than primary research journals [37].

\section{Statistical reliability of journal citation measures}

The use of journal citation measures naturally leads to the question of whether any reliability could be defined for comparing and ranking of scientific journals based on the indicator values.

Since journal citation measures considerably depend on the citation practices established in a given field, it is assumed that a comparison has sense only if the compared journals represent the same subject matter and if possible also have similar characteristics (e.g. they publish original research).

Citations could be considered as random events and described by an appropriate distribution. It has been shown that citation frequency follows a negative binomial distribution [2]. In this case the Impact Factor is a sample mean which is approximately normally distributed (provided the sample size is large enough, which in practice means that a journal publishes more than 10 articles in the period of consideration). The standard deviation ( $D$ ) of an IF is determined by the sample size, $f_{0}$ (fraction of uncited papers) and the IF itself. Two impact factors $I F_{1}$ and $I F_{2}$ differ significantly if the absolute value of the normally distributed test statistics

$$
W=\left(\mathrm{IF}_{1}-\mathrm{IF}_{2}\right) /\left(D_{1}^{2}+D_{2}^{2}\right)^{1 / 2}
$$

exceeds a threshold value corresponding to a given confidence level. An example of a comparison of journal impact factors in the field of elementary particle physics is shown in Table 4 . A confidence level of 0.95 is chosen (the threshold value is then 1.96). Only the impact factors of the two Italian journals (Lettere al Nuovo Cimento and Nuovo Cimento $A$ ) do not differ significantly at the given confidence level.

Such a comparison of impact factors of journals in the same subject field could be considered as a step from a pure quantitative measuring to a 'qualitative' one. Using the same approach, i.e. applying a convenient stochastic model, a statistical reliability could be determined also for more complicated indicators (e.g. influence weights). The calculation of test statistics is more complex than that for the impact factor presented here.

\section{Table 4}

$W$-values ${ }^{a}$ for four physics journals in 1980 (On the diagonal are 1980 impact factors)

\begin{tabular}{lccll}
\hline Journal Title & 1 & 2 & 3 & 4 \\
\hline 1. Lettere al Nuovo Cimento & 0.753 & & & \\
2. Nuovo Cimento A & 0.08 & 0.759 & & \\
3. Physical Review D & 19.6 & 18.6 & 2.654 & \\
4. Zeitschrift für Physik B & 47 & 4.6 & 2.1 & 2.059 \\
\hline
\end{tabular}

a The test statistics values are calculated using data from Scientometric Indicators [57]. 


\section{Correlation between journal citation measures}

A recent paper [12] analyses the relationship between citation rate on the one hand, and impact factor and immediacy index. on the other. It points out that journal rankings by impact factor and uncorrected rates of citation do not differ significantly. The random sample is between 5 and 6 percent of all SCI journals and the titles are ranked according to the indicators mentioned without distinguishing their subject matter, orientation, and type. This may be the reason for the similar rankings by citation rate and mean citation rate.

Studying 63 social science journals. Gordon [44] has found relatively high correlation values for citation rate and impact factor. and significant correlations between citation rate and immediacy index, and between impact factor and immediacy index.

The correlation among 11 journal citation measures and characteristics of 88 psychology journals has been analysed [37]. The citation indicators used were: II. IF. Price Index, $R / P$, self-cited rate and consumption factor. The authors have obtained a reasonably good correlation between IF and II. as well as between consumption factor and its components.

\section{Correlation between citation measures and objec- tive quality criteria for journals}

Objective criteria (excluding the most obvious which appears to be the scientific value of individual papers: quality, topicality, etc.) include editorial standards, journal origin and orientation, type of research covered, age, degree of specialization, circulation size and reprint distribution, etc. Few attempts are made to relate these criteria to the citations received by a journal. Anderson et al. [49] have found that journals listing specific requirements for manuscript acceptance and describing their referee system have higher impact factors. However, this indicator (IF) does not discriminate between journals that publish different type of (biomedical) research.

In the field of psychology a relatively low correlation has been observed between citation indicators (II, IF, Consumption Factor, $R / P$, and selfcited rate) and such journal characteristics as age, number of articles published (size), and circulation size [37]. The authors have suggested, however, that "the Consumption Factor may reflect the relative quality of journals whose primary orientation is the popular dissemination of collective research findings" [37, p.358].

\section{Relation between citation-based and subjective evaluation of scientific journals}

Several techniques are applied for subjective journal evaluation (selection and ranking). Observation of library use [11]. examination of profiles of subscribers to SDI services [7,9.18], and questionnaire-based studies [40] are among the most frequently used methods for gathering information on use (for current awareness or retrospective search on a certain topic). According to some authors [49] library use and user judgement methods differ from peer assessment. In a comprehensive review Singleton [4] has described and discussed different techniques to evaluate use of physics journals. The author has compared resulting rankings with those based on journal citation measures (taking different choices of citing sources and ranking methods). Rank correlations have then been determined using Spearman's coefficient and the fraction of titles in common (in the first twenty listed journals). Except for two examples of a fairly good correlation Singleton has found a rather low correlation between subjective (user preference) and citation-based evaluation. The reasons appear to be the dissimilar objec ives of the studies and the difference in time or as the author puts it "citation rankings tend to date fairly rapidly" [4, p.285]. An important suggestion though. namely that measures of current use would correlate better with journal citation measures is confirmed [28].

In a later study [51] it is noted that scientists' evaluation of the average influence per article is in close agreement with citation ratings by impact factor and influence per paper. These findings are sufficient for the authors to validate "citationbased measures serving as surrogates for the average performance of scientific journals".

Other authors have demonstrated that citation analysis is a useful tool in assessing current and potential journal use (by a heterogeneous group in a departmental library), and described the possi- 
ble use of citation data and measures for immediate collection maintenance and development decisions [42].

Gordon [44] has also noticed a strong association between users' evaluation and citation ranking by traditional measures such as citation rate, IF. II, and number of published items. The author has reached the conclusion that citation analysis could be applied to journal selection for libraries and secondary services.

Journal usefulness in physics (as reported by a group of American and Canadian physicists) has been estimated using a quantitative model [5]. In this model (of multiple regression type) only traditional journal citation measures from JCR are included.

Subjective approaches and corresponding measures (based on observation of library use or value judgements in surveys) suffer from some limitations [52] and are traditionally confined to a small sample. Library use studies do not differentiate between current awareness and retrospective search. The main problems of using surveys are related to lack of theoretical framework. low response rate, inflation owing to desirability, etc. [52]. Or as the authors put it "it is impossible to know if differences across studies are due to differences among samples, populations or the scales themselves".

On the other hand, objectivity of citation analysis is also not evident and is not synonymous with accuracy and validity [52]. In view of this reality Garfield has reached the conclusion that "all that can be done, and perhaps all we can expect to do, is to compare results of different methodologies and attempt to find significant correlations between them" [19].

\section{Comments on journal citation analysis}

Journal citation analysis is a bibliometric and scientometric method using references in scientific journals as a tool for constructing (rather general) measures of journal relationships and relative impact. It is based on the assumption that journal references are related (in one way or another) to the use of these journals by the population of authors and are "a reflection of scientific community's work and interests" [20, p.247]. Merits and limitations of (journal) citation analysis are widely discussed [20, p. 244-250] as citation counts or measures as used for selection and ranking of journals (e.g. by librarians and information scientists). Citation rankings of journals are resorted to for such purposes as the study of the structure of a discipline [45] or to evaluate individual and group performance [23].

The introduction of JCR as an index based on grouping and summation of condensed citations widely extended the use of citation analysis as available data made tedious counting unnecessary. At the same time biases towards preliminary measurement intentions [15. p.195] are discarded as original data in SCI (and SSCI) are not compiled for journal evaluation. The choice of citing sources and time periods of observation permit broad studies (even across disciplines) of journal relatedness and impact using citation measures readily available, or constructing new ones for a specified purpose of investigation. Journal rankings based on citation measures prove to be more international and not easily obtainable by other methods [4]. This is also related to the wide use of English as a language of science. Citation analysis (of journals) appears to be "better suited to answer the kinds of questions which generally lead to efforts to rank journals" [52, p.323].

Most of the critics of journal citation analysis are concerned with lack of accuracy and validity [52, p.322], and possible bias because of such extraneous factors as journal affiliation, circulation, age. etc.

It is well known that citations to one journal are unevenly distributed, i.e. a small proportion of its articles attract a large fraction of citations. Using statistical averages such as IF or II (without precision in their deviations) in such cases could be misleading. Differences of citation rates are often related to scientific 'quality' as well as to topicality and controversial character of an article or group of articles. Variations in citation patterns and traditions affect citation rates and makes comparisons across disciplines impossible. Citation measures even in the same subject field can be influenced by the choice of citing sources and the time period of observation.

Citation counts could be simply biased toward journal titles available in local library collections or processed by information services (especially by Current Contents). References given are related to authors' opinions and beliefs, and are somewhat 
rarely the result of a "supra-national and suprapersonal consideration" [6, p.70]. Editors" instructions may also influence the choice of journal titles or exhaustive references, e.g. reference lists. may be truncated because of extra publication charges involved. This makes citation analysis complex but problems "can be solved satisfactorily with a reasonable amount of methodological and interpretative effort" [20, p.241] and by preserving (somehow) the "fine structure" of the citation data through to the final (interpretative) stages of the investigation [30].

\section{References}

[1] A.E. Cawkell, Evaluating scientific joumals with Journal Citation Reports - a case study in acoustics. J. Amer. Soc. Info. Scl. 29 (1) (1978) 41-46.

[2] A. Schubert and W. Glänzel. Statıstical reliabılıty of comparisons based on the impact factor of scientific publications, Scientometrics 5 (1) (1983) 59-74.

[3] A. Schubert and W. Glänzel, Mean Response Time - a new indicator of journal citation speed with application to physics journals. Czech. J. Phisics B 36 (1)(1986) 121-125.

[4] A. Singleton, Joumal ranking and selection: a review in physics, J. Document. 3? (4) (1976) 258-289

[5] B.C. Bennion and S. Karschamroon. Multivarate regression models for estimating joumal usefulness in physics. J. Document. 40 (3) (1984) 217-227.

[6] B. Cronin. The Citation Process (Taylor Graham, London, 1984).

[7] B. Stefaniak, Need for pnmary periodicals as determined by SDI. J. Chem. Info. Comput. Sci. 21 (1) (1981) 39-40.

[8] C.B. Osborn. The place of the journal in the scholarly communications system. Libran Res. Techn. Serices 28 (4) (1984) 315-324

[9] C. Danilowicz and H. Szarski, Selection of scientıfic journals based on the data obtained from an information service system. Info. Proc. Manag. 17 (1) (1981) 13-20.

[10] C.E. Burke and D. de S. Price. The distribution of citations from nation to nation on a field by field basis - a computer calculation of the parameters. Scientometrics 3 (5) (1981) 363-377.

[11] C.J. Mankin and J.D. Bastulle. An analysis of the differences between density-of-use ranking and raw-use ranking of library journal use, $J$. Amer. Soc. Info. Sa. 32 (3) (1981) 224-228.

[12] C. Tomer. A statistical assessment of two measures of citation: the impact factor and the immediacy index, Info. Proc: Manag. 22 (3) (1986) 251-258

[13] D. de S. Price. Citation measures of hard science, soft science, technology and non-science, in: C.E. Nelson and D.K. Pollock, ed., Commumcation Among Scientists and Engmeers (Heath. Lexington, MA, 1970) 3-22.

[14] D. de S. Price, Toward a model for science indicators, in: Y. Elkana et al., ed.. Toward a Metric of Science (Wiley, New York. 1978) 69-95.
[15] D. de S. Price. The citation cycle, in: B.C. Griffith. ed. Key Papers in Information Science (Knowledge Ind. Publ.. White Plans, NY, 1980) 195-210.

[16] D. de S. Price. The analysis of square matrices of scientometnc transactions. Sctentometrics 3 (1) (1981) 55-63.

[17] D.K. Gapen and S.P. Milner, Obsolescence, Library Trends 30 (1) (1981) 107-124.

[18] E. Garfield, Citation statistics may help scientists choose journals in which to publish, in: E. Garfield, Essay of an Information Scientist, l'ol. I (ISI Press, Philadelphia. PA, 1977) 268-269.

[19] E. Garfield. M.V. Malin and H. Small. Citation data as science indicators, in: Y. Elkana et al., ed.. Toward a Metric of Science: The Adient of Science Indicarors (Wiley, New York, 1978) 179-207.

[20] E. Garfield. Citation Indexing - Its Theory and Applicauon in Science. Technology, and Humanities (Wiley, New York. 1979).

121) E. Garfield, Journal citation studies: 36. Pure and applied mathematics journals: what they cite and vice versa, Current Contents (15) (1982) 5-13.

[22] E. Garfield, Why the Joumal Citation Reports?, Currem Contents (17) (1983) 9-12

[23] E. Garfield. How to use citation analysis for faculty evaluations, and when is it relevant?. Current Contents (44) (1983) 5-13, and (45) (1983) 5-14.

[24] E. Garfield. The 1982 articles most cited in 1982 and 1983: 2. Physical sciences, Current Contents (48) (1984) $3-14$.

[25] E. Garfield. The 1983 articles most cited in 1983 and 1984: 2. Physical sciences, Current Contents (50) (1985) 3-19.

[26] E. Garfield, The evolution of physical chemistry to chemical physics, Current Contents (3) (1986) 3-12.

[27] E. Noma, An improved method for analyzing square scientometric transaction matrices, Scientometrics 4 (4) (1982) 297-316.

[28] E. Pan. Joumal citation as a predictor of joumal use in libranes. Collection Management ? (1) (1978) 29-38.

[29] G. Hirst, Discipline impact factors: a method for determuning core journal lists. J. Amer. Soc. Info. Sct. 29 (4) (1978) 171-172.

[30] G. Holton, Can science be measured, in: Y. Elkana et al.. ed.. Tonard a Metric of Science (Wiley. New York, 1978) 39-68.

[31] G. Pinski and F. Narin. Citation influence for journal aggregates of scientific publications. Info. Proc. Manag. 12 (5) (1976) 297-312.

[32] G. Pinski, Citation based measures of research interactivity, Screntometrics 2 (4) (1980) 257-263.

[33] H.M. Artur, "Halbwertzent wissenschaftlicher Literatur" - Naturgesetz oder Forschungsartefakt?. Nachr. Dokumentation 34 (2) (1983) 79-86.

[34] H. Small and E. Garfield. The geography of science-discıplınary and national mappings, J. Info. Sct. $1 /$ (4) (1985) 147-160.

[35] H. Zeisel, Difficulties in indicator construction: notes and queries, in: Y. Elkana et al., ed., Toward a Metric of Science (Wiley, New York. 1978) 253-258.

[36] I. Asai, Adjusted age distribution and its application to 
impact factor and immediacy index. J. Amer. Soc. Info. Scl. 32 (3) (1981) 172-174.

[37] J.C. Smart and C.F. Elton. Consumption factor scores of psychology journals, Scientometrics 4 (5) (1982) 349-360.

[38] J. Marton, Causes of low and high citation potentials in science: citation analysis of biochemistry and plant phys.ology journals, J. Amer. Soc. Info. Scl. 34 (4) (1983) $244-246$

[39] J. Ziman. Public Knowledge (Cambridge University Press, Cambridge. 1968).

[40] K.C. Mace and H.D. Wamer, Ratings of psychology journals, American Psychologist 28 (1973) 184-186.

[41] K. Subramanyam, The scientific journal: a review of current trends and future prospects. UNESCO Bull. Libraries 29 (4) (1975) 192-201

[42] K.W. McCain and J.E. Bobick, Patterns of journal use in departmental library - a citation analysis. J. Amer. Soc. Info. Scl. 32 (4) (1981) 257-267.

[43] M.B. Line and A. Sandison, 'Obsolescence' and changes in the use of literature with tume. J. Document. 30 (3) (1974) 283-350.

[44] M.D. Gordon. Citation ranking versus subjective evaluation in the determination of journal hierarchies in the social sciences, J. Amer. Soc. Inf. ScI. 33 (1) (1982) 55-57.

[45] M.P. Carpenter and F. Narin. Clustering of scientific journals, J. Amer. Soc. Info. Scr. 24 (6) (1973) 425-436.

[46] N.L. Geller, Citation influence methodology of Pinski and Narin, Info. Proc. Manag. 14 (2) (1978) 93-95.

[47] N. Pravdic and R. Pekorari, The citing practices of the authors to the national journals in mathematics, physics, and chemistry, Sctemometrics $8(3 / 4)(1985) 233-246$.

[48] P.B. Slater, Hierarchical clustering of mathematical journals hased upon citation matrices, Scientometrics 5 (1) (1983) 55-58.

[49] P.J. Anderson and R.K. Goldstein, Criteria of Journal quality, J. Research Commun. Stud 3 (1/2) (1981) 99-110.

[50] P.N. Servi and B.C. Griffith. A method for partitioning the journal literature. J. Amer. Soc. Info. Sci. 2I (1) (1980) $36-40$.

[51] P.R. McAllıster, R.C. Anderson and F. Narin, Comparison of peer and citation assessment of the influence of scientific journals, J. Amer. Soc. Infor. SCl. 31 (3) (1980) $147-152$

[52] R.A. Weishelt and R.M. Regol,. Ranking journals, Scholarly Publishing (July 1984) 313-325.

[53] R. Todorov, Condensed matter physics journals, Sctentometrics 5 (5) (1983) 291-301.

[54] R. Todorov, Determination of influence weights for scientific journals. Sctentometrics 6 (2) (1984) 127-138.

[55] R. Todorov. Review journals in physics, Czech. J. Phy'sics $B 36$ (1) (1986) 157-162

[56] S.N. Mehta and S.P. Gupta. Scientific pernodicals: their problems and future prospects. Informatologia rugoslarka /2 (1/2) (1980) 7-16.

[57] T. Braun, W. Glänzel and A. Schubert. Scientometric Indicators (World Scientific, Philadelphia, PA. 1985).

[58] V.I. Yanovsky. Citation analysis significance of scientific journals, Scientometrics 3 (3) (1981) 223-233. 